\title{
A Constituição De 1988 e seus Corolários Legislativos em Matéria Urbanística: O Plano Diretor em épocas dos grandes eventos futebolíticos e esportivos
}

\author{
Luigi Bonizzato* \\ Dimitrios Elias Zenelis ${ }^{\star \star}$ \\ Julia lunes \\ Luciana Silveira Ardente
}

Sumário: Resumo. Abstract. 1. A Constituição de 1988, sua complementação legislativa e estrutura urbanística. 2. Planos Diretores e o advento da Copa do Mundo de 2014 como grande evento esportivo no Brasil. 3. Bibliografia.

\section{RESUMO}

A Constituição brasileira de 1988 foi normativamente generosa, muito embora a eficácia de várias de suas normas dependa de complementação legislativa pelo legislador infraconstitucional. E, tal tarefa, a ser primeira e inicialmente executada pelo Congresso Nacional, finda por se associar à característica e tradição do Poder Legislativo brasileiro, ligada à elaboração de inúmeras leis, com base na mais próxima influência romano-germânica sobre a formação do Direito brasileiro. Neste cenário, o Plano Diretor, previsto na mesma Constituição da República como instrumento básico para a consecução da política urbana no âmbito municipal, assumiu papel fundamental a partir do momento em que o Estatuto da Cidade, complementador da Constituição, condicionou a eficácia de várias de suas normas à existência do citado Plano Diretor. E este, lei de fundamental importância, mas ainda subutilizada no país, merece especial exame, sobretudo, especificamente, aqueles relacionados aos municípios que sediarão a Copa do Mundo de 2014. Seu exame é passo fundamental para uma abordagem juridicamente precisa e crítica sobre como 0

\footnotetext{
Professor Adjunto de Direito Constitucional da Faculdade de Direito e do Programa de PósGraduação em Direito (PPGD) da Universidade Federal do Rio de Janeiro (FND/UFRJ). Doutor em Direito pela Universidade do Estado do Rio de Janeiro (UERJ). Coordenador, na mesma Instituição de Ensino Superior, dos Projetos de Pesquisa intitulados "Plano Diretor $e$ Constituição" e "Constituição de 1988 e seus Direitos Sociais: interdisciplinaridade e Constitucionalização do Direito".

Graduando em Direito pela Faculdade de Direito da Universidade Federal do Rio de Janeiro (FND/UFRJ). Pesquisador e Membro do Grupo de Pesquisa denominado "Plano Diretor e Constituição".

Graduanda em Direito pela Faculdade de Direito da Universidade Federal do Rio de Janeiro (FND/UFRJ). Pesquisadora e Integrante do Grupo de Pesquisa denominado "Processo Legislativo e complementação constitucional", vinculado ao Projeto de Pesquisa denominado "Constituição de 1988 e seus Direitos Sociais: interdisciplinaridade e Constitucionalização do Direito".

Graduanda em Direito pela Faculdade de Direito da Universidade Federal do Rio de Janeiro (FND/UFRJ). Pesquisadora e Integrante do Grupo de Pesquisa denominado "Plano Diretor e Constituição".
} 
ordenamento jurídico e a sociedade brasileira vêm encarando e enfrentando o desenvolvimento e o crescimento urbano de suas cidades.

Palavras-chaves: Constituição de 1988; complementação legislativa; Poder Legislativo; Plano Diretor; Copa do Mundo de 2014.

\section{ABSTRACT}

The Brazilian Constitution of 1988 was normatively generous, although the effectiveness of several of its standards depends on legislative complementation by the legislator. And, such a task, to be first and initially executed by the National Congress, ended by associating the characteristic and tradition of Brazilian Legislative Power, linked to the development of countless laws, based on more next influence Roman Germanic-about the formation of the Brazilian Law. In this scenario, the Director Plan, laid down in the same Constitution of the Republic as a basic instrument for the achievement of urban policy at the municipal level, assumed fundamental role from the moment in which the Status of the City, like a Constitution complementation, has taken its toll on the effectiveness of several of its standards to the existence of the aforementioned Plan Director. And this, law of fundamental importance, but still underutilized, deserves special consideration, especially, specifically, those related to municipalities that will receive the 2014 World Cup. Its examination is a crucial step for a legally precise and critical analysis about how the legal system and the Brazilian society is approaching and experiencing the development and urban growth in their cities.

Key words: 1988 Constitution; legislative complementation; Legislative Power; Director Plan; the 2014 World Cup. 


\section{A Constituição de 1988, sua complementação legislativa e estrutura urbanística.}

A lógica urbanístico-constitucional brasileira é dotada de peculiaridades e características que, se de um lado dela fazem um verdadeiro estatuto constitucional sobre Direito Urbanístico, de outro, escancaram vertentes positivas e negativas, suficientes e insuficientes, enfim, adequadas e inadequadas para a garantia e tutela do considerável número de pessoas que vive nos centros urbanos brasileiros. É certo que o Brasil não se resume a suas capitais e regiões metropolitanas, sobretudo as mais populosas como Rio de Janeiro e São Paulo, pois, para muito além delas, há municípios - milhares, ressalte-se -, cidades, importantes áreas rurais ${ }^{1}$ e, também, urbanas, embora de tamanhos menores se comparadas aos megalópoles acima citadas. Mas, de qualquer forma, o fato é que, ao trazer expressiva quantidade de normas que regulam de forma mais ou menos direta o ambiente urbano, a Constituição de 1988 deixou estampada sua generosidade normativa e, pelo menos, tentativa de regulação de políticas e medidas de caráter urbanístico.

$E$, neste contexto de variedade de normas, uma categoria merecerá especial destaque no presente estudo: a relativa ao Plano Diretor, entregue pelo legislador constituinte originário à competência municipal. Este único Plano Urbanístico previsto expressamente e, ao mesmo tempo, genericamente regulamentado no texto constitucional vigente, detém fundamental relevância teórica e, a nível prático, embora sob duras penas e percalços, ganha espaço, dia após dia, em agendas políticas, sociais e econômicas dos numerosos governos locais espalhados por este país de dimensões continentais. O Plano Diretor ainda não é uma realidade perfeita, acabada e elogiável talvez na maioria absoluta dos municípios brasileiros. Entretanto, ainda que de forma equivocada, imprópria ou, até mesmo, indevida, algum Prefeito e/ou Câmara dos Vereadores, respectivamente, Poderes Executivo e Legislativo municipais, já deve ter, na pior hipótese, ventilado a possibilidade de sua criação e, por corolário, de cumprimento e respeito às normas legais brasileiras vigentes, que

\footnotetext{
${ }^{1}$ A palavra importante aqui utilizada de modo inicialmente descompromissado com uma maior precisão, mas já se pensando em nuanças econômicas, sociais e culturais, entre outras.
} 
obrigam os municípios a elaborarem seus Planos Diretores e a reverem-no decenalmente.

Não se pode olvidar que o Brasil, embora tão influenciado pelo Direito anglo-saxão e pelo que de lá veio e continua a vir $^{2}$, possui marcante e indiscutível tradição romano-germânica. $E$ isto quer dizer que na lei deve residir o Direito por excelência, o que faz com que o trabalho legiferante de todos os Poderes Legislativos do Estado Federal brasileiro produzam leis que, atualmente, já atingem, somente no nível federal, o patamar aproximado de 13.000 (treze mil). Sem se contar espécies normativas outras, hoje previstas no Art. 59 da Constituição da República e em inúmeras outras antigas Constituições do país também cogitadas em artigos outros dos respectivos textos constitucionais brasileiros. Além, também, de demais normas acessórias como Decretos regulamentares - na história brasileira infelizmente com suas funções muitas vezes desviadas -, Portarias, Resoluções etc.

Para se ter uma ideia mais precisa sobre a mencionada produção legislativa, mas com foco mais direcionado à complementação das normas constitucionais pelo legislador federal brasileiro, pesquisa aguçada e aprofundada sobre a produção legislativa no Brasil, da entrada em vigor da Constituição de 1988 até o ano de 2012, mostra números realmente relevantes. $^{3}$ Indagações e questionamentos foram feitos e as respostas

\footnotetext{
${ }^{2}$ Inúmeras teorias, por exemplo, norte-americanas, sempre foram e continuam em pleno aproveitamento pelos teóricos e estudiosos brasileiros. Já na própria Constituição de 1891, denominada Constituição da República dos Estados Unidos do Brazil - à época, a grafia era exatamente esta, ou seja, Brasil com "z" mesmo - foram importadas inúmeras normas, variados institutos e diversos modelos político-jurídicos dos ainda recentes Estados Unidos da América. A forma republicana de governo, a tripartição dos Poderes em Executivo, Legislativo e Judiciário, a forma de Estado federal, o controle difuso de constitucionalidade (este chegado pouquíssimos anos depois da entrada em vigor da Constituição de 1891, mais precisamente, em 1894), são apenas alguns exemplos da marcante influência dos Estados Unidos da América na formação política e jurídica do novo Estado brasileiro. E, ressalte-se, todos os institutos, modelos e características citados, por mais incrível - ou não - que possa parecer, continuam válidos e existentes até os dias de hoje, mantidos na ordem jurídica brasileira por todas as demais Constituições do Brasil, a saber: 1934, 1937, 1946, 1967, 1969 (Emenda Constitucional no 01/69) e 1988.

${ }^{3}$ Os dados quantitativos da pesquisa foram extraídos do site (site: http://www2.planalto.gov.br/) do planalto, o qual disponibiliza uma relação das leis ordinárias e complementares produzidas em cada ano, além de indicar as leis que, naquele período, receberam alguma mensagem de veto, isto é, em termos mais precisos, algum tipo de veto por parte do Presidente da República, chefe do Poder Executivo nacional e a quem cabe o poder de vetar leis ordinárias e
} 
indicam para um cenário a ser considerado em qualquer estudo que, de forma mais ou menos direta, verse sobre as leis brasileiras, a complementação da Constituição e a eficácia de suas normas. Embora várias tenham sido as referidas indagações investigativas e, igualmente, múltiplas as respostas e diversos os resultados, para os fins aqui pretendidos e, tendo em vista, sobretudo, o exame final objetivado, ligado aos Planos Diretores enquanto leis municipais complementares de natureza urbanística, intimamente vinculados à estrutura constitucional reservada ao Direito Urbanístico no Brasil, apenas três indagações e respostas serão a seguir consideradas.

A primeira indagação a que a pesquisa se propôs a responder questionava o número de leis ordinárias e complementares ${ }^{4}$ produzidas no período de vigência da atual Constituição, com a indicação comparativa dos respectivos percentuais. O resultado apontou a existência de 5.132 leis ordinárias e 84 leis complementares produzidas durante todo o período de vigência da atual Constituição (conforme já anunciado, da entrada em vigor da Constituição de 1988 ao ano de 2012, período este utilizado para toda a pesquisa, de acordo com os resultados também a seguir relacionados), o que significa, em termos percentuais, $98,4 \%$ de leis ordinárias e 1,6\% de leis complementares. Restou clara a conclusão de que as leis ordinárias representam quase que a totalidade das leis produzidas, enquanto as leis complementares são produzidas em quantidade bastante inferior.

Já a segunda indagação a que a pesquisa se propôs a responder referiu-se ao número de leis ordinárias e complementares, produzidas durante o mesmo período de tempo escolhido, que receberam veto total, parcial ou, ainda, nenhum veto. Quanto às leis ordinárias, o resultado demonstra 257 leis

complementares em sentido técnico, conforme previsto no já referido Art. 59 da Constituição da República. $O$ banco de dados do planalto também fornece informações acerca das leis que receberam mensagem de veto presidencial total, conforme também examinado na investigação procedida e, a seguir, melhor explanado.

4 Imperioso desde logo ressaltar que, no entendimento dos autores, leis ordinárias e complementares são reputadas leis infraconstitucionais, de mesmo patamar hierárquico, com diferença entre as duas categorias instalada em duas características: reserva material constitucional específica para o caso de leis complementares e campo residual destinado às leis ordinárias; e quórum legislativo qualificado - maioria absoluta - exigido para a aprovação de leis complementares pelo Poder Legislativo nacional e de maioria simples (ou relativa) para a aprovação de leis ordinárias. 
totalmente vetadas, 416 leis parcialmente vetadas e 4.716 leis sem nenhum veto, revelando que $4,77 \%$ das leis ordinárias aprovadas pelo Congresso foram totalmente vetadas pelo Presidente da República; 7,72\% foram parcialmente vetadas; e $87,51 \%$ não receberam qualquer tipo de veto. No tocante às leis complementares, 07 leis foram totalmente vetadas, 20 leis parcialmente vetadas e 64 leis não foram alvo de qualquer veto, revelando que 7,35\% das leis complementares aprovadas pelo Congresso Nacional brasileiro foram totalmente vetadas pelo Poder Executivo; 21,78\% foram parcialmente vetadas; e $70,87 \%$ não foram vetadas.

Por fim, a terceira indagação girou em torno do número e a porcentagem de leis complementares expressas e leis complementares não expressas, produzidas no período de vigência da atual Constituição. Para os fins da investigação procedida, cabe explicar que lei complementar expressa é a que decorre de expressa previsão constitucional, ou seja, de claro mandamento constitucional para a atuação infraconstitucional legislativa por meio de lei complementar. E leis complementares não expressas aquelas criadas pelo Congresso Nacional brasileiro, em um primeiro momento e sob uma inicial análise, sem vinculação a qualquer dispositivo constitucional que exija uma lei denominada complementar como necessária à complementação da norma inserida na Constituição. O resultado apontou para 74 leis complementares expressas e 10 leis complementares não expressas, com a revelação de $88,1 \%$ de leis complementares expressas e $11,9 \%$ de leis complementares não expressas. Os valores percentuais, neste sentido, indicam que a grande maioria das leis complementares produzidas estão vinculadas a uma previsão constitucional, a um dispositivo na Constituição que expressamente exigiu a elaboração de lei complementar para tratamento e regulação de determinada matéria ${ }^{5}$.

\footnotetext{
${ }^{5}$ Em contrapartida, uma minoria de aproximadamente $12 \%$ dessas leis complementares não estão vinculadas a qualquer dispositivo constitucional que estabeleça a necessidade de elaboração de lei complementar para o caso respectivo. Na realidade, apesar de a pesquisa procedida ter enfrentado de perto tal problemática ligada à utilização - entendida como indevida - de leis complementares sem qualquer previsão para sua utilização em algum dispositivo constitucional, vale aqui, por fim e, por conseguinte, salientar, que essas leis complementares não expressas poderiam ter sido leis ordinárias, mas por uma escolha do legislador, foram criadas como leis complementares.
} 
Pois bem, as breves considerações apenas realçadas deixam claro que a quantidade de normas existentes no Brasil é grande e isto, sem dúvida, sempre e tradicionalmente reflete e refletiu em toda estrutura social, econômica, política, jurídica, cultural etc. do país. Entretanto, se, por um lado, às vezes se escuta de cidadão “isto está na lei!", por outro lado, reações contrárias, máxime de poderes maiores, há anos invocam o excesso de leis como sendo ainda faltante e lacunoso, o que exigiria, praticamente, a contrario sensu, uma atuação mais marcante de setores do Estado - diga-se, de maneira precisa, do Poder Judiciário - para a harmonização e solução de conflitos. Este último fato, quem sabe, até mesmo a ser considerado um paradoxo, ainda que falso ou meramente imposto como verdade incontestável - leva também à criação de uma estrutura favorável à defesa de determinados interesses dentro do Estado dito democrático nacional.

Contudo, muito embora a temática que envolva, atualmente, a atuação marcante, decisiva e criadora do Poder Judiciário seja de grande interesse acadêmico e prático, ora somente se menciona tal dinâmica para fins de apoio ao objeto central desta pesquisa. Na realidade, ao se chamar a atenção para as tradições, sobretudo romano germânicas do Direito brasileiro, quer-se apenas mostrar que lei deve possuir a importância que lhe cabe, pois não foi à toa que logo o parágrafo único do Art. 1ำ da Constituição vigente deixou claro que "todo poder emana do povo que o exerce por meio de representantes eleitos ou diretamente, nos termos desta Constituição". Ora, se uma das grandes dificuldades dos Brasil do século XXI é, sem dúvida, cumprir-se a lei e que se refira aqui, diretamente, aos seus principais aplicadores formais, isto é, Poderes Executivo e, principalmente, Judiciário -, tem-se que, o quanto antes, aprender-se a conviver com uma estranha realidade, na qual a lei é o instrumento que cria direitos e obrigações, que inova no ordenamento jurídico e, ao mesmo tempo, com sua desvalorização por meio da grande liberdade conferida aos julgadores, liberdade esta que, há algum tempo, era até denominada, pelos autores deste trabalho, como discricionariedade, em seguimento a clássicas teorias sobre o Direito, a maioria das quais produzidas 
alhures $^{6}$, mas que, hoje, é entendida como real livre convencimento por meio de valores, formações pessoais, crenças, Direito (em seu sentido mais amplo) e, quem sabe, na lei. Naquela há pouco citada lei a quem cabe criar direitos e obrigações a partir dos princípios democráticos escolhidos pelo legislador constituinte brasileiro.

Neste contexto, ao se falar, portanto, nas inovações constitucionais em matéria urbanística e, paralelamente, na magnitude do Plano Diretor enquanto lei municipal reservada ao estabelecimento de diretrizes gerais para 0 desenvolvimento urbano de cada município, não se pode esquecer de levar em conta o cenário acima brevemente pincelado, em relação ao qual, certamente, vários trabalhos aprofundados e de qualidade existem, tanto no Brasil, quanto fora dele, conforme já anteriormente citado. Repita-se, o Plano Diretor é considerado lei complementar municipal, que goza, inclusive e, portanto, de quórum qualificado para ser aprovado junto à respectiva Câmara dos Vereadores, materialização do Poder Legislativo no âmbito municipal.

Mas, se uma pequena e até tímida problemática inicial se lança pelo que acima se expôs, outras questões há que exigem e trazem à tona uma série de outras indagações e desdobramentos.

A Constituição de 1988, conforme acima dito, é verdade, foi normativamente generosa e, em matéria urbanística, não obstante múltiplas críticas possam aqui ser feitas, uma das quais a da própria insuficiência de normas, criou capítulo específico para as chamadas Políticas Urbanas. Associado às diversas outras normas que de forma mais ou menos imediata versam sobre Direito Urbanístico (competências municipais, direitos fundamentais sociais, direitos de liberdade etc.), tem-se o que acima já se

\footnotetext{
${ }^{6}$ Sobre o tema, conferir, entre tantos outros, os clássicos: DWORKIN, Ronald. Los Derechos em Serio. Barcelona: Editorial Ariel S.A., 1997.; ALEXY, Robert. El concepto y la validez Del Derecho. Barcelona: Gedisa, 1997.; ALEXY, Robert. Teoria de los derechos fundamentales. Madrid: Centro de Estudios Constitucionales, 1993.; LARENZ, Karl. Metodologia da Ciência do Direito. 2. ed. Lisboa: Fundação Calouste Gulbenkian, 1989.; e CANARIS, Claus-Wilhelm. Pensamento sistemático e conceito de Sistema na ciência do Direito. Tradução de António Menezes Cordeiro. 02. ed. Lisboa: Fundação Calouste Gulbenkian, 1996.
} 
intitulou estatuto constitucional urbanístico. Mas tal estatuto, como não poderia deixar de ser, sobretudo se levada em conta a natureza constitucional dessas normas, finda por exigir, em alguns casos, necessária complementação infraconstitucional, fato que, se examinado de forma ampla, leva à formação não apenas de um estatuto, mas também de um verdadeiro bloco de normas, que se inicia na Constituição e, praticamente, não encerra, pois, no mais específico nível e no menor grau hierárquico, alcança Decretos municipais, entre outros instrumentos normativos que se multiplicam com rapidez e em espaços variados. Nesse quadro, assim, pode-se proceder a uma análise um tanto quanto crítica, do ponto de vista jurídico, da estrutura normativa criada para o Direito Urbanístico no Brasil, a partir do Plano Diretor.

Nesse viés, a investigação que se segue embalará com a mencionada análise da posição e eficácia das normas constitucionais sobre Direito Urbanístico, com foco direcionado à figura do Plano Diretor e, em seguida, dedicar-se-á, de forma mais direta, ao exame atual e necessário, inserido em já e a partir de quase duas décadas da entrada em vigor da Constituição de $1988^{7}$, dos Planos Diretores dos municípios brasileiros que sediarão a Copa do Mundo de 2014. O objetivo é a tentativa de verificação do grau de compreensão dos criadores dos respectivos Planos Diretores, assim como do nível de comprometimentos dos mencionados Planos, com um dos maiores eventos esportivos, midiáticos e turisticamente atrativos existentes no mundo, rivalizando apenas em grandiosidade com as também tradicionais Olimpíadas, que, apesar de terem sede no Rio de Janeiro em 2016, não serão objeto direto (mas paralelo, pois o Plano Diretor do Rio de Janeiro será alvo de exame pelo fato de tal cidade sediar também jogos da Copa do Mundo de 2014) de análise no presente estudo a fim de que não se estenda o mesmo para além dos objetivos inicialmente propostos, embora seja inegável a proximidade temática ${ }^{8}$.

\footnotetext{
${ }^{7}$ A Constituição, atualmente, se aproxima das três décadas de existência, mas o estudo proposto voltará às citadas quase duas décadas de vigência da mesma Constituição da República.

${ }^{8}$ A escolha por não enfrentar, neste texto, o Plano Diretor do Rio de Janeiro com foco voltado para as Olimpíadas de 2016 é realmente proposital, apesar dos Grupos de Pesquisa dos quais participam os autores deste trabalho já terem procedido a inúmeras pesquisas sobre o tema. De qualquer forma, em alguns momentos, poderá ser natural a menção a alguns pontos
} 
Assim, a primeira análise a ser feita versa sobre a aplicabilidade do estatuto constitucional urbanístico a partir da exigência de criação, pelos municípios, dos respectivos Planos Diretores, plano urbanístico nacional por excelência ${ }^{9}$. Frise-se, é claro, nacional no sentido de sua previsão na Constituição na República e, não, logicamente, por seu raio de abrangência, indubitavelmente municipal e, portanto, local, como pretendeu o legislador constituinte originário.

Primeiramente, entretanto, vale tecer importante observação sobre o acima já mencionado Estatuto da Cidade, o qual pode ser reputado o inicial, imediato e principal complementador do texto constitucional em matéria urbanística. Boa parte de suas normas, mais precisamente, daquelas que trazem os pelo próprio Estatuto denominados instrumentos de política urbana, dependem, para sua utilização por cada um dos municípios brasileiros, respectivamente, da criação do Plano Diretor pelo município interessado e de posterior lei municipal específica sobre o assunto. Assim, se muito se questiona sobre a aplicabilidade e efetividade, validade e vigência das normas constitucionais, a complementação específica e direcionada ocorrida a partir da criação do Estatuto da Cidade, ao invés de, em um primeiro momento, já sanar eventual inaplicabilidade, em vários casos apenas a estendeu, pois condicionou a eficácia das próprias e primeiras normas complementadoras da Constituição à criação de outras. Umas das quais, talvez as mais importantes, as que se encontram presentes no documento legal que ora se enfoca: o Plano Diretor.

Portanto, além de o Estatuto da Cidade vincular a eficácia de vários de seus dispositivos à elaboração de leis municipais específicas, também atrelou grande parte da possibilidade de aplicabilidade plena de suas normas ao Plano

comuns entre Copa do Mundo e Olimpíadas, mas, logicamente, no estudo do Plano Diretor do Rio de Janeiro, cidade na qual, reforce-se, coincidirão os dois maiores eventos esportivos do mundo.

${ }^{9}$ Tal expressão deriva do fato de ter sido o Plano Diretor o único plano urbanístico citado e genericamente regulado na Constituição de 1988, fato de perto acompanhado pela principal complementação infraconstitucional sobre matéria urbanística, qual seja, o Estatuto da Cidade, Lei $\mathrm{n}^{\mathrm{o}} 10.257 / 2001$. 
Diretor. Percebe-se, desta maneira, que a existência de um Plano Diretor, nos termos da previsão contida na Constituição da República brasileira, é requisito indispensável para a plena aplicabilidade do Estatuto da Cidade e, por consequência, das próprias normas constitucionais por ele complementadas. Em outras palavras, em matéria urbanística, a linha de eficácia das normas constitucionais, na maioria dos casos, finda por exigir não apenas a participação do legislador infraconstitucional federal, ou seja, da União, mas também e, necessariamente, dos municípios, a quem a mesma Constituição de 1988 entregou a competência preponderante e específica em matéria urbanística.

Certamente e disso não restam dúvidas, por ser o Estatuto da Cidade uma lei federal de caráter nacional, todos os Planos Diretores existentes deverão a ele se amoldar e, os que estão por vir, com ele não poderão conflitar.

Em breve síntese do regime jurídico estatutário conferido ao Plano Diretor $^{10}$, o Art. 41 do Estatuto da Cidade assim estatui:

\begin{abstract}
Art. 41. O plano diretor é obrigatório para cidades: I - com mais de 20.000 (vinte mil) habitantes; II - integrantes de regiões metropolitanas e aglomerações urbanas; III - onde o Poder Público municipal pretenda utilizar os instrumentos previstos no parágrafo $4^{\circ}$ do Art. 182 da Constituição Federal; IV - integrantes de área de especial interesse turístico; V - inseridas na área de influência de empreendimentos ou atividades com significativo impacto ambiental de âmbito regional ou nacional; $\mathrm{VI}$ - incluídas no cadastro nacional de Municípios com áreas suscetíveis à ocorrência de deslizamentos de grande impacto, inundações bruscas ou processos geológicos ou hidrológicos correlatos.
\end{abstract}

\footnotetext{
${ }^{10}$ Não obstante, por questões metodológicas, não sejam aqui total e diretamente examinados, o Estatuto da Cidade traz outros dispositivos que versam sobre o regime jurídico do Plano Diretor, nos quais se encontram normas variadas, inclusive as que fazem menção à necessidade de participação popular no seu processo de elaboração, tão relevantes do ponto de vista jurídico e social. Além disso, a Lei 12.608 de 10 de abril de 2012, já fez acréscimos à redação original do Estatuto da Cidade em material de Plano Diretor. Tais alterações, embora também não objeto de exame direto neste estudo, versam, sobretudo, sobre a necessidade de os Planos Diretores atentarem para regiões de encostas e locais onde o risco, por exemplo, entre outros, de desabamentos e deslizamentos possa colocar em risco a vida de famílias e moradias existentes. Tais alterações, reforce-se, foram diretamente motivadas pela maior tragédia natural ocorrida na história brasileira recente: a da região serrana do Estado do Rio de Janeiro, com foco principal nas cidades de Nova Friburgo, Teresópolis e Petrópolis.
} 
E o Art. 182, caput e parágrafo primeiro, da Constituição, assim determina:

\begin{abstract}
Art. 182. A política de desenvolvimento urbano, executada pelo Poder Público municipal, conforme diretrizes gerais fixadas em lei, tem por objetivo ordenar 0 pleno desenvolvimento das funções sociais da cidade e garantir o bem- estar de seus habitantes.

$\S 1 \%$. O plano diretor, aprovado pela Câmara Municipal, obrigatório para cidades com mais de vinte mil habitantes, é o instrumento básico da política de desenvolvimento e de expansão urbana.
\end{abstract}

No que diz respeito, assim e, inicialmente, aos municípios com mais de vinte mil habitantes, de acordo com o previsto no Estatuto, juntamente com o estatuído pela Carta Magna pátria, aqueles que não possuírem Plano Diretor e desejarem lançar mão dos instrumentos de política urbana estatutários, deverão, primeiramente, elaborar o Plano Diretor, a partir do qual passaria a ser possível a criação dos supra ditos instrumentos estatutários, com, logicamente, o cumprimento de eventuais demais exigências previstas em lei, tal como é, por exemplo, a de criação de leis municipais específicas.

Por outro lado, cumpre destacar que um município, com menos de 20 mil habitantes, não poderia ser obrigado, somente pelo exame do texto constitucional, a elaborar um Plano Diretor. Entretanto, considerando que a criação de um Plano Diretor, em teoria, é tido como algo positivo, fomentador do desenvolvimento urbano qualitativo, estimulador do crescimento de uma cidade com respeito ao bem-estar social e à qualidade de vida de seus habitantes, mesmo um município com menos de vinte mil habitantes pode ser obrigado a criar o referido Plano, caso se enquadre nas hipóteses previstas nos inciso II a VI do Art. 41, acima transcrito, do Estatuto da Cidade. Eventual questionamento acerca da própria constitucionalidade de tais incisos esvair-seia a partir do acima exposto embasamento, repita-se, segundo o qual, pelo menos em teoria, a criação de um Plano Diretor atende à principiologia constitucional e urbanística brasileira, independentemente do número de habitantes do município. 
Enfim, sob enfoque constitucional, em acréscimo ao já esboçado, não se deve olvidar que os parágrafos primeiro e segundo do Art. 182 da Constituição de 1988 definem as fronteiras e o conteúdo básico do Plano, considerando-se sempre às funções sociais da propriedade.

Imperioso assim concluir que a criação do Plano Diretor é de competência exclusiva dos Municípios, fato este corroborativo da obrigatoriedade exclusiva de os municípios atuarem em prol de sua elaboração e consecução. E, realce-se, na linha do já devidamente aduzido, todas as leis municipais complementares ao Estatuto da Cidade deverão, por corolário, estar em consonância e seguir as orientações expressamente definidas pelo Plano Diretor respectivo.

Portanto, com nitidez se infere que da decisão de elaborar um Plano Diretor, lei municipal também específica, depende toda a viabilidade pragmática do Estatuto da Cidade, o qual deposita suas fichas na tarefa legisladora municipal, a qual deverá dissociar-se de pressões e interesses abstrusos e não atinentes ao consentâneo desenvolvimento municipal, para servir de rijo e forte apoio à implementação de uma qualidade de vida mais direcionada aos anseios da totalidade da população do município, e não apenas às necessidades de setoriais classes abastadas, receosas, dia após dia, décadas após décadas, séculos após séculos, de perder as regalias com as quais convivem desde os primórdios da formação social brasileira.

E, se estas breves considerações acima tiveram por objetivo deixar clara a relevância e magnitude do intitulado plano urbanístico brasileiro por excelência, com quase duas décadas de existência da Constituição de 1988, muitos e variados ainda são os vícios que giram em torno dos Planos Diretores. $E$, nas vésperas dos dois próximos maiores eventos esportivos do planeta, a se realizarem em terras nacionais, como não observar e avaliar como reagiram os municípios brasileiros à chegada da Copa do Mundo de 2014 e às Olimpíadas de 2016? Conforme acima exposto, entretanto, no presente estudo as atenções se voltam para as cidades-sede da Copa do Mundo de 2014, muito embora o 
Rio de Janeiro congregue a presença do evento futebolístico e dos jogos olímpicos de 2016.

$E$, para a fim de melhor se entender o que ora se pretende demonstrar, passa-se a uma prévia abordagem sobre a anunciação e chegada da Copa do Mundo de 2014 no Brasil.

É o que se frisará, em sequência.

\section{Planos Diretores e o advento da Copa do Mundo de 2014 como grande evento esportivo no Brasil.}

Ressalte-se que, após inúmeras e acirradas negociações no âmbito desportivo internacional, sobretudo entre eventuais países interessados em sediar a Copa do Mundo em 2014, apresentou-se o Brasil como candidato único e, no final de outubro de 2007, a Fédération Internationale de Football Association (FIFA) confirmou o país como sede do mencionado evento futebolístico de 2014 (e, consequentemente, da denominada Copa das Confederações, ocorrida no ano de 2013).

A partir de então, começou o Brasil, em sua totalidade, a conviver com a nova realidade: sediar, depois de mais de 50 anos, novamente e, sob um contexto político, econômico e social bem distinto, um evento esportivo de tamanha grandeza ${ }^{11}$. Ou seja, foi iniciada a discussão acerca da viabilidade estrutural, social e urbana brasileira para sediar um evento desse porte. Se óbvias e necessárias melhorias nos serviços públicos e nos equipamentos urbanos seriam possíveis e, ainda, se poderiam ser aproveitadas após a Copa do Mundo em prol dos interesses da população brasileira e, não somente, dos organizadores e frequentadores do evento, de duração certamente não maior do que 30 dias.

\footnotetext{
${ }^{11}$ Vale ressaltar que, embora relevantes e também de significativa grandeza, os Jogos Pan Americanos, ocorridos recentemente no Brasil e, mais precisamente, na cidade do Rio de Janeiro, não são capazes de rivalizar em tamanho e desdobramentos variados com a Copa do Mundo e, logicamente, também com as Olimpíadas.
} 
Diante deste panorama, então, de tantas obras e transformações, sobretudo urbanas, que supostamente trariam melhorias para várias cidades brasileiras, dúvidas também nasceram e inúmeras questões foram trazidas às agendas políticas, econômicas, sociais e jurídicas do país. Uma delas, entretanto, de maneira mais diretamente voltada sobre o que ora se debruça, versou e, naturalmente, versa, sobre como as legislações federal, estadual e municipal encaram um evento de tal nível. Em outras e mais precisas palavras, o entendimento é o de que devem constar nas respectivas leis que versem sobre o desenvolvimento urbano, por exemplo, diretrizes bem definidas que, a partir da escolha do Brasil como sede da Copa do Mundo de 2014, busquem fomentar, estimular, promover e garantir as funções sociais da cidade, além de igualmente garantir o bem-estar daqueles que nela habitam, como estabelece 0 Art. 182, caput da Constituição brasileira. Com a necessária lembrança de um foco direcionado para as cidades escolhidas como sedes da Copa do Mundo de 2014. Assim e, enfim, pensando-se já na figura dos Estados federados e, principalmente, dos municípios brasileiros, Leis Orgânicas Municipais, Planos Diretores e Constituições Estaduais, entre outros documentos legais que poderiam ainda ser citados, estariam adaptados para tal tipo de evento, com a necessária previsão e contemplação de novos planejamentos e desenvolvimentos em um país cujas cidades ainda sofrem com um número consideravelmente elevado de problemas urbanos, tais como deficiente transporte público e coletivo, violência urbana, insuficiente saneamento básico etc.?

De acordo com o já levantado, na própria Constituição da República e, com maior concentração, em seus artigos 182 e 183, estão definidos os parâmetros a serem seguidos pela Política Urbana no Brasil. Dentre tais parâmetros, também conforme acima destrinçado, encontra-se o dever de criação do Plano Diretor, instrumento básico da política de desenvolvimento e de expansão urbana, pelas cidades com mais de vinte mil habitantes. Nele, devem estar previstas diretrizes gerais que orientem o desenvolvimento das funções sociais da cidade e da garantia do bem-estar de seus habitantes. 
Portanto, nessa linha de análise das previsões não somente constitucionais, mas também infraconstitucionais, deveriam estar contidas, em cada Plano Diretor, máxime já nos relativos a municípios potenciais candidatos a sedes de grandes eventos esportivos, orientações e regulações acerca da realização e acontecimento desses eventos, tal como é, no caso ora mais diretamente abordado, a Copa do Mundo de 2014. E, ressalte-se, com ainda mais força e imperatividade, nos Planos Diretores dos municípios brasileiros após sua escolha como sede oficial do torneio futebolístico de 2014.

Ao se analisar o Estatuto da Cidade, como anteriormente também suscitado, percebe-se que sua normatividade é de conteúdo amplo, fato intimamente ligado ao fato de ser o referido Estatuto portador de normas gerais sobre matéria urbanística, o que também confere às suas normas um maior $\mathrm{e}$ necessário raio de aplicação, incidência e abrangência, sobretudo em um Estado Federal de dimensões continentais como o Brasil. Destarte, não são encontráveis dispositivos que tragam especificações e maiores detalhamentos acerca de eventos esportivos do nível, exempli gratia, da Copa do Mundo da FIFA. Suas menções e previsões às áreas que podem vir a ser fortemente afetadas com um evento desta natureza referem-se ao desenvolvimento urbano cotidiano, ou seja, relacionado ao decorrer natural do tempo, sem citação a qualquer evento específico. A título ilustrativo, a breve menção ao lazer no Art. 2º, inciso I, segundo o qual: "Art. 2‥ A política urbana tem por objetivo ordenar o pleno desenvolvimento das funções sociais da cidade e da propriedade urbana, mediante as seguintes diretrizes gerais: I - garantia do direito a cidades sustentáveis, entendido como o direito à terra urbana, à moradia, ao saneamento ambiental, à infraestrutura urbana, aos transportes e aos serviços públicos, ao trabalho e ao lazer, para as presentes e futuras gerações".

Em direção a uma legislação mais específica, encontram-se, por exemplo, de acordo com o já salientado, as Constituições Estaduais, as Leis Orgânicas Municipais e os Planos Diretores de cada município que possuir mais de vinte mil habitantes, além de leis municipais e outras normas de 
caráter mais local. Assim como o Estatuto da Cidade, as Constituições Estaduais e as Leis Orgânicas Municipais portam, sobre matéria urbanística, normas gerais sobre infraestrutura urbana respectiva e gradativamente mais ou menos genéricas, conforme, logicamente, seu raio de abrangência e finalidades precípuas. Mas, certamente, normas específicas de eventos esportivos como a Copa do Mundo de 2014 também não estarão presentes em tais legislações. Na Constituição do Estado do Amazonas, diz-se que investimentos relacionados à infraestrutura básica e 0 apoio ao desenvolvimento de atividades produtivas (podendo-se, quiçá, aqui enquadrarse um evento como a Copa do Mundo da FIFA) cabem ao Poder Público, podendo ser concedida tal competência ao setor privado a fim de satisfazer tais necessidades ${ }^{12}$ Enfim, em relação, principalmente, aos Planos Diretores, podese então esperar que haja, aí sim e, portanto, o que as demais legislações mencionadas não são naturalmente capazes de fazer, isto é, trazer previsões acerca de um evento esportivo como a Copa do Mundo de 2014, uma vez que, inclusive, resta estabelecido, no próprio Art. 40, §3ํㅡㄹ do Estatuto da Cidade, que "a lei que instituir o Plano Diretor deverá ser revista, pelo menos, a cada 10 (dez) anos", fato este que confere aos Planos Diretores característica marcante de acompanhamento normativo urbanístico da dinâmica urbana dos vários municípios brasileiros.

Neste sentido, pode-se, finalmente, chegar ao exame dos Planos Diretores dos municípios brasileiros que já sabidamente sediarão jogos da Copa do Mundo de $2014^{13}$. Mas com a antecipação de uma triste constatação: embora pudessem os referidos municípios valerem-se deste importante instrumento normativo chamado Plano Diretor, a maioria das sedes dos jogos da Copa do Mundo de 2014, novamente, deixaram escapar valiosa oportunidade de planejamento urbanístico adequado, sobretudo a partir de uma ordenação mais precisa de seu território e de uma busca pelo atendimento das

12 "Art. 162. É da responsabilidade do Poder Público a realização de investimentos para a formação de infraestrutura básica e de apoio necessários ao desenvolvimento das atividades produtivas, podendo, em casos especiais, expressamente autorizados pelo Legislativo, proceder concessão para explorar, transferir ou de legar competência para esse fim ao setor privado".

${ }^{13}$ São doze os municípios: Rio de Janeiro, São Paulo, Curitiba, Porto Alegre, Manaus, Cuiabá, Brasília, Fortaleza, Natal, Belo Horizonte, Recife e Salvador. 
funções sociais da cidade e da garantia do bem-estar social de suas habitantes, conforme previsão estampada no Art. 182 da Constituição da República.

Nos próximos parágrafos, assim, verificar-se-ão os Planos Diretores dos municípios brasileiros que sediarão a Copa do Mundo de 2014, com a final e desde $o$ início anunciada abordagem de suas normas e eventuais comentários sobre determinadas construções e obras urbanas específicas ${ }^{14}$.

Nesse viés, no Plano Diretor do município de Belo Horizonte, lançado em 1996, constam normas que estão fortemente ligadas ao desenvolvimento urbano da cidade em meio a uma Copa do Mundo. Dentre elas, merecem realce as previsões contidas no Art. $7^{\circ}$ e incisos III, IV, V XI e XVIII, que fazem referência à infraestrutura da cidade, máxime no que tange aos transportes e ao desenvolvimento de grandes empreendimentos; no Art. 9ㅜ, incisos XII e XIV, os quais referem-se à qualidade de vida dos habitantes; no Art. 11, inciso VI, que estabelece a construção e ampliação de autódromos, hipódromos e estádios esportivos; no Art. 19, inciso VI, o qual estabelece que se deve facilitar as vias de acesso ao lazer, principalmente entre os municípios vizinhos e a área central; no Art. 33, que, ao longo de seus incisos, determina os parâmetros a serem seguidos no desenvolvimento do turismo; e no Art. 39, incisos II, III, V e VI, que versam sobre as políticas de esporte e lazer, incluindo-se o incentivo às competições olímpicas de caráter internacional. Entre todos os acima citados dispositivos, chama-se especial atenção, entretanto, para o inciso XI, do Art. $7^{\circ}$ e para o inciso XII, do Art. 9015. Em tais incisos, verifica-se a preocupação com a promoção de atividades econômicas, desde que estas não venham a prejudicar o desenvolvimento urbano. Com

\footnotetext{
${ }^{14}$ Saliente-se que eventuais mudanças anunciadas, nas linhas e notas de rodapé seguintes, não são, de forma alguma, aqui valoradas como positivas, suficientes ou adequadas tanto para a recepção da Copa do Mundo de 2014, quanto para a população brasileira, no período pósCopa do Mundo. Tratam-se de meras citações, a partir, sobretudo, da realidade vivenciada com base na relação entre o exame de cada Plano Diretor com políticas de governo adotadas ao longo dos últimos anos.

${ }^{15}$ Decretam, tais dispositivos, que deve ocorrer o controle das condições de instalação das diversas atividades urbanas e de grandes empreendimentos, minimizando as repercussões negativas, além da instalação de atividades econômicas de forma a evitar prejuízos à qualidade de vida da população, ao ordenamento urbano e à integridade física da infraestrutura urbana.
} 
base em tais dispositivos, entende-se que as melhorias e construções necessárias para um evento que se enquadre nas categorias legais citadas devem estar em compatibilidade com as particularidades da cidade e da região ${ }^{16}$.

Em relação à capital do Brasil, ou seja, ao Distrito Federal (Brasília), seu Plano Diretor determina, em seu Art. 109, inciso III, que a região do estádio (Setor de Clubes e Estádios Esportivos Sul - SCEES) é parte da chamada estratégia de dinamização, a qual, no caput do art. 106, está voltada à configuração de novas centralidades, promovendo o desenvolvimento urbano, econômico e social e a indução do crescimento local e regional, mediante a diversificação do uso do solo, a implantação de centros de trabalho e renda e a melhoria dos padrões de mobilidade e acessibilidade, observada a capacidade de suporte socioeconômica e ambiental do território. ${ }^{17}$

Mais uma cidade sede da Copa do Mundo de 2014 é Cuiabá, cujo Plano Diretor, promulgado em 1992, sofreu modificações até o ano de 2005, ou seja, antes da escolha do Brasil como sede da Copa do Mundo. Portanto, não há dispositivos que façam referência direta a eventos esportivos do nível e grandeza da Copa do Mundo. Encontram-se apenas, em seus dispositivos iniciais, clássicas definições, tais como as referentes a direitos dos cidadãos, dentre outros, ao lazer, ao transporte coletivo, à segurança e à participação, os quais possuem, por sua própria natureza social, algum envolvimento com tal evento esportivo. Entretanto, a única referência aos esportes está no Art. 20, inciso VII, do Plano Diretor de Cuiabá, de acordo com o qual "constituem diretrizes específicas do desenvolvimento urbano na área de Recreação e Lazer (...) a articulação das Secretarias Municipais de Educação e Promoção

\footnotetext{
${ }^{16}$ A título de acréscimo, para além das diversas diretrizes de desenvolvimento urbano previstas no Plano Diretor vigente do município de Belo Horizonte, merecem também destaque as previsões de reforma descritas no Plano de Mobilidade Urbana para a Copa de 2014.

17 Também a título de informação, ressalte-se que uma das metas previstas no Plano Diretor de Brasília está na ampliação da malha viária, com a implementação dos chamados VLTs (Veículo Leve sobre Trilhos), os quais ligarão a área central com o interior, algo, frise-se, bastante destacado nos dispositivos do Plano Diretor, fazendo inclusive parte dos princípios previstos no referido Plano, de acordo, por exemplo, com o previsto no Art. 18, inciso IV: "promover a implementação da integração multimodal dos serviços do sistema de transporte coletivo".
} 
Social, no sentido de promover a utilização das ruas de pedestres, praças e demais logradouros públicos como espaços onde possam se desenvolver atividades desportivas e de recreação infantil. Exemplo: pintura, teatro de marionetes e outros principalmente aos sábados, domingos e feriados ${ }^{18}$.

Curitiba, outra sede da Copa do Mundo de 2014, no seu Plano Diretor, não menciona eventos esportivos de tal porte, até porque foi este alterado, pela última vez, em dezembro de 2004, conforme também já identificado em outros municípios estudados, os quais foram revisado antes da definição do Mundial no Brasil. Desde 2010 há proposta de alteração do respectivo documento, mas até o momento da conclusão do presente artigo, não foi concretizada. Portanto, nele há apenas previsões de melhorias nos serviços públicos a fim de se aprimorar a qualidade de vida da cidade. Diretrizes traçadas pelo Plano Diretor curitibano que envolvem atividades preparatórias para tal evento encontram-se resumidas no art. $4^{\circ}$, com destaque para a participação do povo (Art. 4ํㅡㄹ inciso IV). Já no Art. 6o, inciso XV, do mesmo Plano, é determinado que se deve "privilegiar os gastos públicos nas áreas que melhor proporcionem a melhoria da qualidade de vida a todos os cidadãos". Tal especificação deixa subentendida a importância de se relacionar um evento de tamanha repercussão com a realidade da cidade. Ou seja, evitarse obras que não venham a ter utilidade após a realização dos jogos.

A cidade de Manaus, em comunhão com a acima e já citada cidade de Cuiabá, é uma das que mais geram dúvidas quanto à realização de jogos da Copa do Mundo. Tal dúvida gira em torno do fato de que a cidade não possui atividades esportivas que ganhem destaque no painel brasileiro. Por tal fato, as reformas que estão sendo realizadas na região colocam em xeque uma futura utilização, por exemplo, do estádio no qual ocorrerão os jogos. Logo, em seu Plano Diretor, pouquíssimas são as citações quanto às reformas e melhorias

\footnotetext{
${ }^{18}$ Talvez a cidade em relação à qual maiores críticas sejam direcionadas relativamente a investimentos com um estádio de futebol seja mesmo a cidade de Cuiabá, onde há real preocupação com a utilização posterior do estádio, ou seja, após o término da Copa do Mundo.
} 
na área dos esportes, mantendo o foco em áreas como turismo, transportes, saúde e segurança pública ${ }^{19}$.

Natal, a capital do Rio Grande do Norte, em seu Plano Diretor, também não possui diretrizes criadas especialmente para eventos esportivos do nível de uma Copa do Mundo. Na Lei Complementar que o estabelece, o Art. $3^{\circ}$, inciso III, afirma que os critérios definidos ao longo desta lei e da Lei Orgânica do Município devem respeitar, dentre outros, "a racionalização e adequação do uso da infraestrutura urbana instalada, evitando-se sua sobrecarga e ociosidade". Tal dispositivo reflete a preocupação com o desenvolvimento de obras e com a realidade e as particularidades da região. Logo em seguida, na Seção II do mesmo Plano Diretor, estão determinados os chamados empreendimentos de impacto, os quais provocam fortes alterações no espaço. Além disso, criam-se destaques para os aperfeiçoamentos nas áreas dos transportes, saúde e turismo. Há um critério peculiar em tal Plano: não há especificações acerca de atividades esportivas. Visto que tal lei é de 1994, entende-se que alterações a fim de corrigir tal erro já deveriam ter sido realizadas, pois o Estatuto da Cidade define como tempo máximo de reexame dos Planos Diretores o período de 10 anos.

Assim como a maioria dos Planos Diretores das cidades-sede, o da capital gaúcha, Porto Alegre, também não foi atualizado a partir do momento em que foi divulgado o Brasil como sede da Copa do Mundo de 2014, tendo sua publicação ocorrido em 1999. Entretanto, a fim de aprimorar as reformas a serem realizadas na região, previu-se a criação de um Plano Diretor de Turismo, no qual diretrizes para um crescimento do interesse dos turistas em visitar a região após os jogos da Copa seja uma realidade.

\footnotetext{
${ }^{19}$ O Vivaldão foi o estádio escolhido para a realização dos jogos. Entretanto, este foi demolido para que se construísse uma nova arena. Como a repercussão do futebol na região não é em grande escala, há a ideia de que as obras seriam um imenso desperdício do dinheiro público, visto que os gastos não seriam cobertos pela iniciativa privada. Além dos problemas já citados e de outros ligados aos transportes e à mobilidade urbana, por exemplo, deve-se promover em maior grau o combate ao desmatamento, visto que obras já estão acarretando inúmeras e potenciais destruições e danos ao meio ambiente.
} 
Mais uma cidade sede da Copa do Mundo de 2014 foi Recife. A revisão do Plano Diretor da capital pernambucana ocorreu em 2008. Apesar de ser uma das mais recentes, não foi capaz de aproveitar, ainda, qualquer anunciação do Brasil como sede da Copa de 2014. Por isso, não se encontram dispositivos específicos, como é o caso de alguns Planos Diretores acima já estudados. É uma cidade com um forte potencial turístico, o que beneficiou os investimentos para as obras de infraestrutura da cidade. O grande desafio de tal cidade é a correlação e convivência harmoniosa entre o futebol e a parte histórica da cidade, visto que a arquitetura de um estádio ao nível dos utilizados para a Copa não é tão harmônica se levado em conta o panorama histórico e a arquitetura da cidade. Como estatuído no Art. 4ำ do seu Plano Diretor, a sustentabilidade urbana deve se apoiar "na potencialização da criatividade e do empreendedorismo para o desenvolvimento da economia, da cultura, do turismo, do lazer e dos esportes".

O Rio de Janeiro, por sua vez, cidade brasileira com maior exposição turística internacional, possui o Plano Diretor mais atualizado entre as cidadessede dos jogos da Copa do Mundo de 2014 (data de fevereiro de 2011). Por isso, há dispositivos que versam justamente sobre a Copa (e até mesmo sobre as Olimpíadas de 2016), como o parágrafo único do Art. 217 (" $A$ implementação da Política de Transportes do Município contemplará todos os projetos da área de transportes que serviram de base para a candidatura da Cidade a sede das Olimpíadas, em 2016, e a uma das sedes da Copa do Mundo, em 2014".). Violência urbana, melhoria dos transportes públicos e coletivos e da infraestrutura em geral são também desafios do município, o qual integra a segunda maior região metropolitana do país.

Em relação ao Plano Diretor, criado em 2002, a vizinha São Paulo traz os seguintes destaques que envolvem áreas de potencial interesse para os fins ora propostos:

Artigo 9ำ, parágrafo único, inciso IV - Criação de pontos de atração turística é função do município.

Artigos 17 e 18 - Desenvolvimento do setor turístico. 
Artigo 19, incisos II e III - Criação de infraestrutura necessária para execução de atividades relacionadas a eventos de atração turística. Artigo 43, incisos I, III e V - Política dos esportes: adequação da capacidade dos equipamentos para grandes eventos e espetáculos esportivos.

Artigo 44, inciso II - Revitalização de Interlagos, Pacaembu, Centro Olímpico.

Artigo 117, $\S 1^{\circ}$ - Bom funcionamento dos transportes para os não envolvidos com os grandes eventos.

Com relação à Salvador, o seu Plano Diretor é o que mais faz referência à infraestrutura dos complexos esportivos, apesar de a sua alteração em 2008 não apresentar citações expressas à Copa do Mundo de 2014. Artigos como o 11 e o 136 trazem especificações genéricas em relação ao assunto ao tratar da política de desenvolvimento econômico do município, tendo como partes das suas diretrizes gerais o investimento nos transportes, no turismo e nas demais atividades econômicas, a fim de reforçar o planejamento e a operação de seus instrumentos. Além disso, saliente-se a região do canal de Cotegipe até a Enseada do Cabrito, coma previsão do direcionamento da implementação de programas para instalação de centros culturais, entretenimento, lazer, turismo e complexos esportivos.

Por fim, o décimo segundo Plano Diretor aqui examinado: o do município de Fortaleza ${ }^{20}$. Na linha, igualmente, da maioria dos onze Planos Diretores examinados anteriormente, em matéria de grandes eventos esportivos e, portanto, da Copa do Mundo de 2014 percebe-se uma generalidade em suas normas. $O$ seu Art. 53 trata do incentivo ao turismo através da cultura, do lazer e do esporte. Já dos artigos 196 ao 200 há citações acerca de projetos especiais e do estudo de impacto da vizinhança. Enfim, determina que devem ser elaborados planos específicos para cada área de atividade econômica, dois anos após a promulgação do Plano Diretor, algo a

\footnotetext{
${ }^{20}$ Merece aqui ser ressaltada a dificuldade de acesso ao Plano Diretor de Fortaleza, sobretudo em tempos de evolução significativa dos meios eletrônicos e digitais de acesso a informações. Tal dificuldade, realce-se, pode ser inclusive reputada uma afronta ao princípio constitucional da publicidade, previsto no artigo 5 da Constituição da República, além de um desrespeito às próprias normas contidas no Estatuto da Cidade e que estabelecem o dever de publicização e fácil acesso da população ao Plano Diretor. Pasme-se, o acesso (muito trabalhoso, que se ressalte) via internet, mostrou uma completa falta de edição e formatação, sua disponibilização parcial em fotografias, com trechos, inclusive, manuscritos.
} 
ser fiscalizado, sobretudo pela população de Fortaleza, mais proximamente interessada na consecução de suas normas.

Em resumo - depois do exame de 12 Planos Diretores, relativos às 12 cidades-sedes da Copa do Mundo de 2014 -, o que se percebe, em suma, é que os Planos Diretores, documentos e instrumentos legais de tamanha importância e utilidade para a organização urbana, foram e continuam sendo indevida e inadequadamente explorados. A falta de interesse em colocá-los em prática ou de até mesmo atualizá-los dentro do prazo de dez anos estipulado em lei (Estatuto da Cidade) demonstra tal patente descaso. Fica cada vez mais evidente que se encontra em crescente consolidação um verdadeiro caos em relação às políticas urbanas, as quais não são devidamente estudadas e aplicadas pelos administradores públicos brasileiros, sobretudo os municipais, a quem compete a preponderância em matéria urbanística, conforme fartamente estabelecido na Constituição brasileira de 1988. Realmente, de nada adianta e adiantará apenas sediar eventos grandiosos como a Copa e, futuramente, os Jogos Olímpicos de 2016, se desafios básicos sociais, econômicos, políticos e, principalmente, jurídicos e legislativos não forem apropriadamente enfrentados e superados, o que vai desde a manifesta carência de manutenção e existência de programas sustentáveis relativos a um sistema de mobilidade urbana, até a implementação eficaz e efetiva de inúmeras políticas públicas, a maioria das quais, atualmente, enquadradas na categoria de direitos sociais, fundamentais e constitucionalmente garantidos, como a saúde, a educação, o lazer, a segurança, entre tantos outros a serem aqui citados e abordados ao longo deste trabalho.

Não se pode também, de forma alguma, incorrer em imprecisões e inocências jurídicas, sociais e políticas. Em outras palavras, o que se quer dizer é que muitos Planos Diretores, de vários municípios brasileiros, independentemente de serem ou não sede de grandes eventos, são, em um primeiro momento, tecnicamente bem elaborados, mas, sob um olhar mais crítico e específico, não contemplam os interesses da maioria da população local. Findam por prestigiar interesses, por exemplo, de grupos de pressão 
específicos - o que não é anormal em uma democracia -, mas sem um necessário equilíbrio de forças com outros grupos sociais - o que é democraticamente prejudicial -, levando à prevalência, por exemplo, em muitos casos, da força do capital sobre o interesse público real da população do respectivo município. Assim, a qualidade técnica de um Plano Diretor não é, certamente, garantia de qualidade na sua elaboração, aprovação e consecução.

O estudo ora proposto, portanto, teve por objetivo final a análise pontual dos Planos Diretores das cidades-sedes da Copa do Mundo de 2014. Mas uma análise jurídica, que permitisse apontar a carência de normas, sua eventual deficiência e possíveis vícios ligados ao respeito à estrutura normativo-urbanística brasileira, iniciada na Constituição da República e finalizada no âmbito das inúmeras leis e atos normativos, construídos no âmbito de cada um dos milhares de municípios brasileiros preocupados com sua organização e desenvolvimento urbano.

E, nada obstante críticas inúmeras possam ser sempre desferidas a vários aspectos de um Plano Diretor, uma das principais, em termos jurídicos e políticos, ainda continua sendo a pouca informação acerca do neste trabalho intitulado principal plano urbanístico brasileiro, seu ainda defeituoso e precário processo de elaboração e, enfim, sua inconsistência do ponto de vista de conexão, inserção e respeito ao sistema de normas urbanísticas brasileiras, entre as quais vale sempre mencionar e repetir a Constituição de 1988 e o Estatuto da Cidade, Lei 10.257/2001.

\section{Bibliografia.}

ALEXY, Robert. El concepto y la validez Del Derecho. Barcelona: Gedisa, 1997.

Constitucionales, 1993. 
ACSELRAD, Henri. Sentidos da sustentabilidade Urbana. In: ACSELRAD, Henri (Org.). A duração das cidades: sustentabilidade e risco nas políticas urbanas. Rio de Janeiro: D.P.\& A. Editora, 2001.

BARBOSA, Ruy. Comentários à Constituição Federal brasileira. São Paulo: Editora Saraiva \& Cia, 1932, 6 v.

BONIZZATO, Luigi, REIS, José Carlos Vasconcellos dos. Direito Constitucional: questões clássicas contemporâneas e críticas. Rio de Janeiro: Editora Lumen Juris, 2011.

A Constituição Urbanística e elementos para a elaboração de uma teoria do Direito Constitucional Urbanístico. Rio de Janeiro: Editora Lumen Juris, 2010.

. O advento do Estatuto da Cidade e conseqüências fáticas em âmbito da propriedade, vizinhança e sociedade participativa. Rio de Janeiro: Editora Lumen Juris, 2005.

CANARIS, Claus-Wilhelm. Pensamento sistemático e conceito de Sistema na ciência do Direito. Tradução de António Menezes Cordeiro. 02. ed. Lisboa: Fundação Calouste Gulbenkian, 1996.

CANOTILHO, J. J. Gomes. Constituição dirigente e vinculação do legislador. Coimbra: Almedina, 1982.

Direito Constitucional e Teoria da Constituição. 07. Ed. Coimbra: Almedina, 2003.

DALLARI, Adilson Abreu, FERRAZ, Sérgio. Estatuto da Cidade. São Paulo: Editora Malheiros, 2002.

DWORKIN, Ronald. Los Derechos em Serio. Barcelona: Editorial Ariel S.A., 1997.

FAORO, Raymundo. Os donos do poder. Vol. I e II. 15. ed. São Paulo: Editora Globo, 2000. 
FERNANDES, Edésio (Org.). Direito Urbanístico. Belo Horizonte: Editora Del Rey, 1998.

FERRAJOLI, Luigi. Derechos y Garantias: la ley del más débil. 03. ed. Tradução de Perfecto Andrés Ibáñez e Andrea Greppi. Madrid: Editorial Trotta, 2002.

FIORILLO, Celso Antonio Pacheco. Estatuto da Cidade comentado. São Paulo: Editora Revista dos Tribunais, 2002.

HARVEY, David. A produção do espaço capitalista. 02. ed. Tradução de Carlos Szlak. São Paulo: Editora Annablume, 2005.

LARENZ, Karl. Metodologia da Ciência do Direito. 2. ed. Lisboa: Fundação Calouste Gulbenkian, 1989.

SARLET, Ingo Wolfgang. A eficácia dos direitos fundamentais. 02. ed. Porto Alegre: Editora Livraria do Advogado, 2001.

SILVA, José Afonso da. Direito urbanístico brasileiro. 03. ed. São Paulo: Editora Malheiros, 2000.

Aplicabilidade das normas constitucionais. 3. ed. São Paulo: Editora Malheiros, 1999.

. Curso de Direito Constitucional positivo. 11. ed. São Paulo: Editora Malheiros, 1996. 